\title{
Communicating Different and Higher across the Praxis of Bloom's Taxonomy While Shifting toward Health at Every Size (HAES)
}

\author{
Ofra Walter ${ }^{1}$, Rinat Ezra ${ }^{2}$ \\ ${ }^{1}$ Tel-Hai Academic College, Kiryat Shemona, Iseral \\ ${ }^{2}$ Independent Researcher, London, UK \\ Email: ofrawa@telhai.ac.il
}

Received 29 May 2015; accepted 26 June 2015; published 29 June 2015

Copyright (C) 2015 by authors and Scientific Research Publishing Inc.

This work is licensed under the Creative Commons Attribution International License (CC BY). http://creativecommons.org/licenses/by/4.0/

(c) (i) Open Access

\begin{abstract}
The majority of recent studies on prevention and control of childhood obesity focus on methods for achieving weight loss. In contrast, the Health at Every Size (HAES) paradigm fosters improved health behaviors for people of all sizes by emphasizing natural diversity of body type and attention to social, emotional, and spiritual factors in addition to physical ones. This study examined introduction of the HAES paradigm to student teachers using different communication models while moving across the learning domains of Bloom's Taxonomy. The qualitative research tested a faceto-face verbal communication model and a Computer-Mediated Communication (CMC) module and its blog. It was also based upon reflection diaries recorded by participants using both models. Participants included Druze, Jewish, and Bedouin students at a teacher training program in northern Israel. The student teachers succeeded in developing the HAES concepts further while demonstrating the higher domain levels across Bloom's Taxonomy. These higher levels emerged when engaging with theoretical concepts and practical dilemmas relating to the HAES concepts of health promotion, body image, well-being, and self-worth. Challenging the appreciation of HAES using different communication models can be translated into diverse contexts of Health Education Practices.
\end{abstract}

\section{Keywords}

Health at Every Size, Bloom's Taxonomy, Communication, Health Promotion, Body Image, Well-Being and Self-Worth, Health Education Practices

\section{Introduction}

While a significant number of research studies have defined childhood obesity as a serious problem and have

How to cite this paper: Walter, O. and Ezra, R. (2015) Communicating Different and Higher across the Praxis of Bloom's Taxonomy While Shifting toward Health at Every Size (HAES). Health, 7, 788-799.

http://dx.doi.org/10.4236/health.2015.76093 
examined various ways of preventing or controlling it, our study of the research on childhood obesity has led us to embrace the paradigm and concepts of Health at Every Size (HAES). HAES is a growing international, transdisciplinary movement whose primary objective is to foster improved health behaviors for people of all sizes, whereby weight loss may or may not be a side-effect [1]. As such, obesity is not intrinsically a problem, and developing preventative and corrective measures to control children's eating habits is not the main goal. HAES concepts include:

- Encouraging body acceptance rather than weight loss or weight maintenance.

- Relying on internal regulatory processes, such as hunger and satiety, as opposed to encouraging cognitively imposed dietary restriction.

- Supporting active embodiment in place of encouraging structured exercise [1].

- Natural diversity in body shape and size.

- Ineffectiveness and dangers of dieting for weight loss.

- The importance of relaxed eating in response to internal body cues.

- The critical contribution of social, emotional, and spiritual as well as physical factors to health and happiness [2].

Methods for communicating the shift toward the HAES paradigm and theoretical concepts have not been fully developed. They deserve further exploration, both globally and locally. Of particular importance is the development of means for communicating HAES to student teachers. Student teachers are in the early stages of forming educational concepts about learning, and their theoretical learning is followed by classroom experience where they can apply what they have learned [3]. The contribution of integrating theory, classroom preparation, and practice in teacher training colleges was demonstrated by Kaufman [4] and by Feiman-Nemser and Buchmann [5], who successfully bridged the gap between practice and academic learning.

Natural appreciation of one's eating choices, body image, size, and self-worth as indicated by the HAES paradigm can be crucial to one's sense of well-being and happiness in early childhood. Yet, the implications of childhood obesity are discussed widely and globally, nearly exclusive of HAES concepts. In the United States, the first lady [6] prioritized the issue of "weight loss in early childhood". In Israel, the location of this study, the education ministry designated the same as the primary education issue for 2011-2012 [7]. Neither national agenda was in line with HAES paradigms. Hence, it is the challenge of this research learning experience to bridge the gap between healthy lifestyle themes promoted nationally and the HAES paradigms. While the healthy lifestyle theme was prioritized by the Israel Ministry of Education, no system-wide pedagogical structure was developed for implementation. Multiple challenges as well as opportunities exist to develop the theme further and create new applied and experimental learning applications involving cognitive, psychomotor, and affective domains. This study examined introduction of the HAES paradigm to student teachers using different models of communication while moving across these three learning domains of Bloom's Taxonomy.

\subsection{Moving across Bloom's Taxonomy While Learning to Appreciate the HAES Paradigm}

To test the introduction, acceptance, and appreciation of the HAES paradigm and its related theoretical concepts and practical dilemmas, we chose to teach HAES applying two different models of communication, a verbal face-to-face communication model and a Computer-Mediated Communication module (CMC) and its blog. We also evaluated the three learning domains of Bloom's taxonomy emerging throughout those applied and experimental learning experiences. These domains are the cognitive, defining knowledge classification, the psychomotor [8]-[10], defining physical skills or task classification, and the affective [11], defining behaviors that correspond to attitudes and values. Affective outcomes tend to be the hardest to articulate initially and often appear difficult to assess at first glance.

In each domain, the three lower levels are knowledge, comprehension, and application. The three higher levels are analysis, synthesis, and evaluation [12]. The model was refined in 2001 and the revision includes several seemingly minor yet actually quite significant changes. The new terms for the levels in the cognitive domain are: Remembering, Understanding, Applying, Analyzing, Synthesizing-Evaluating, and Creating [13].

In the psychomotor domain the learning outcomes related to psychomotor skills are defined as: Observestudents translate sensory input into physical tasks or activities. Model—students are able to replicate a fundamental skill or task. Recognize - students recognize standards or criteria important to perform a skill or task correctly. Standards-Correct-students use standards to evaluate their own performance and make corrections. 
Apply—students apply this skill to real life situations. Coach—students are able to instruct or train others to perform this skill in other situations.

In the affective domain [11] the learning outcomes related to attitudes, behaviors, and values are defined as: Receiving — students become aware of an attitude, behavior, or value. Responding — students exhibit a reaction or change as a result of exposure to an attitude. Valuing — students recognize a value and display it through involvement or commitment. Organizing — students determine a new value or behavior as important or a priority. Characterizing — students integrate the value and recognize it as a part of the person's character.

\subsection{Computer-Mediated Communication (CMC) versus Moderated Verbal Face-to-Face Communication}

Studies have indicated differences in participation, decision making, and personal interactions between group meetings conducted face-to-face and facilitated by a human moderator and group meetings conducted via simultaneous computer-linked discourse and communication.

Potential difficulties in CMC groups have been identified with coordination, given the lack of informational feedback normally facilitated by human moderator/s, absence of social influence and communication codes and cues for controlling discussion, and depersonalization from lack of nonverbal involvement and absence of norms [14]. The primary pitfalls inherent in face-to-face groups where participants generate their ideas verbally, is that participants may be reticent to express their ideas for fear of retaliation or may worry that they will be evaluated or judged by others [15]-[19]. In fact, groups have been found to generate fewer ideas when an authority figure was present [19] and when group members were anxious about social interactions [15].

For this study, we used a CMC called Moodle and its blog. The Moodle is an open source learning method that was introduced into teacher training at the time this research began [20]. CMC is based on socio-constructivist principles [21] [22] and is most suited for an educational approach. Furthermore, the modularity of Moodle and its blog enables teachers to supervise the creation of new activity tools that emerge out of the teacher as a developer setting up those online communications. Halm, Olivier, Farooq and Hoadley concluded that the benefit of CMC is the peer-to-peer mode of collaborative learning and online interactions, which may be beyond the boundaries of our current thought and understanding as to how people interact and construct their ideas online [23].

\section{Purpose}

The purpose of this study was to examine the introduction, acceptance, and appreciation of the HAES paradigm and its theoretical concepts and practical dilemmas to student teachers, using two different models of communication while moving across the learning domains of Bloom's Taxonomy.

\section{Research Questions}

- Whether and how HAES theoretical concepts and practical dilemmas have been extended while moving across the praxis of Bloom's taxonomy.

- In what ways do the different means of communication promote or impede the higher conceptual shifts across Bloom's Taxonomy in relation to the HAES paradigm, concepts and dilemmas.

\section{Methods}

The qualitative study documented in this article is based on the first cycle of an action research project that includes cycles of planning, execution, and evaluation of implementing the HAES paradigm and concepts in the Israeli education system [24]. In this first cycle, students in a teacher training program in Northern Israel were taught HAES concepts and asked to grapple with related practical scenarios and dilemmas. The participants were divided into two groups in order to compare the effectiveness of two different communication models: face-to-face verbal communication and computer mediated communication.

The participating student teachers, educational consultants and researchers came from different cultural backgrounds. Six Druze student teachers and their Druze teaching consultant participated in the session using verbal communication and direct face-to-face brainstorming. This session was followed by smaller focus groups. Both were accompanied and led by two moderators, an Israeli registered dietician nutritionist who was exposed to the 
HAES approach in the UK [25] [26] and previously employed by the Israel Ministry of Education as a district advisor on nutrition and health promotion (1997-2005), and a pedagogical instructor who specializes in early childhood education and the development of early childhood education learning programs. An internet CMC module and related blog containing the same HAES related theoretical and practical scenarios that were introduced to the student teachers participating in the verbal face-to-face communication group was administrated as an electronic task to ten Jewish student teachers and one Bedouin student teacher.

Reflection diaries were kept by both groups on a weekly basis using the CMC.

All 17 student teachers conducted their training in schools in the Northern Israel and Jordan Valley districts and were routinely followed by their pedagogical instructor. A qualitative analysis of the data was made from a content analysis of the students' rich texts from the CMC module and its related blog, the recorded and transcribed discussions of the brainstorming and focus group communications, and from the students' reflection diaries.

\section{Results}

The data was coded and sorted according to the three domains of Bloom's Taxonomy of educational objectives: cognitive, affective, and psychomotor, and then further categorized by themes relating to HAES concepts. The data revealed how the participating student teachers conceptualized and developed the HAES concepts while moving across the learning domains of Bloom's Taxonomy, and while considering in what ways the different communication approaches had promoted or impeded this perceptual development.

\subsection{Cognitive Domain}

The first set of themes demonstrates upward movement through the intellectual skills of Bloom's cognitive domain. Participants analyzed the HAES concepts and broke them down into constituent parts, evaluated or made judgments regarding the concepts, and created or formulated elements of HAES into a new pattern or structure.

Body self-acceptance: Most of the student teachers who completed the electronic module/blog addressed the importance of developing self-acceptance of one's body as the key to happiness regardless of body size: "Accepting the child as he or she is without discriminating between children for any reason whatsoever. In real life we can meet people who are tall and fit with low self-esteem and people who are stocky with higher self-esteem. Happiness and feeling good about oneself aren't necessarily dependent upon physical appearance but upon positive self-esteem". Moreover, the students who took part in the face-to-face focus groups generated suggestions for how to promote body self-acceptance and who should be involved in the effort. They stressed the need for change in social values and for the involvement of educators and parents: "Accepting one's body and self can happen once the social values change, then one's self-values will change. Physical appearance doesn't count as such a big factor when we make decisions in our lives regarding choosing our friends, spouse, or colleagues to collaborate with, etc.; we are not to judge others' physical appearances”. One of the Druze students later noted in her CMC reflection diary: "We ought to help children love themselves and their physical appearance. The main thing is to encourage children to love themselves and their bodies while transmitting this message to the parents who are the first individuals to encourage their children to accept their body and their differences".

Relying on internal regulatory processes of hunger and satiety: The student teachers understood the concept of relying on internal regulatory processes of hunger and satiety. They were also able to evaluate and judge the value of the concept. The student teachers pointed out that children might be confused between hunger and other feelings such as being bored; and, therefore, they suggested teaching them how to distinguish between those feelings. However, their conclusions regarding how to teach children self-awareness of satiety did not always accord with reliance on the children's self-processes, but rather relied upon the significant control of others/ adults over meals times or menu. One participant entered the following comment in her CMC module/blog: "Children often complain about feelings of hunger when they are actually bored and looking for something with which to occupy them. Children need to be taught how to distinguish clearly between feelings of hunger and between having their mouth occupied with something to be able to feel fullness/satiety. Children need to be instructed about fixed meal times and not to bring fast food at all!” Others completing the CMC electronic module/blog entered very constructive ideas of how to account ideally for children's feelings of hunger without necessarily relying upon children's self-processes to become more aware of when they are hungry or, conversely, when they are experiencing satiety and fullness: "To enable children to work with their emotions we must de- 
crease the temptations around them, and that way children will be able to differentiate between their feelings of satiety or, conversely, hunger. To be able to bring children to this point (while the children are still under our responsibility) we must legislate laws requiring children to bring a sandwich, fruit or dairy type beverage to eat during school breaks scheduled at the times they usually become hungry instead of snacks, goodies, etc." The student teachers who participated in the face-to-face verbal communication revealed a much more coherent or functional whole of what can be learned from children in terms of their internal processes relating to sense of hunger or satiety. They asked: "How can we imitate the internal processes and natural curiosity of children" and "How can I facilitate children in sensing when they are hungry or full and then just observe how the child is handling this [without intervening]" and "How can you allow children to control what they eat, once we allow this we can't go back to controlling their eating habits".

The concept discussed here is complex, in part because internal processes such as hunger and satiety, in contrast to external attempts to control and regulate one's eating, are not necessarily cognitive. However, it seems that the additional verbal explanation of that HAES theoretical concept by the moderators of the verbal face-to-face communication group (the researchers in this case) facilitated a high level of comprehension of the HAES concept and its related dilemmas. The researchers encouraged the participants, throughout the brainstorming session and in preparation for the focus groups, to raise dilemmas between the internal and external focus of control in relation to children's eating habits. They asked the students to consider the notion that children naturally eat and drink when they are hungry and thirsty and do not need outside observation of their eating habits.

Supporting active embodiment in place of encouraging structured exercise: During the face-to-face group meetings, the researchers explained, interpreted, exemplified, and compared to alternatives the concept of supporting active embodiment to the student teachers. They used statements such as: "By encouraging activities that are natural to children, you are enabling them to be active without imposing structured exercise. It's not about deciding at the school level that children should have structured exercise 2 - 3 times a week. I, myself, as a nutritionist working with parents and children in the past might have been wrong constructing and later monitoring the frequency of their walks during the week. It's something else; it's like what we were talking about before, starting with babies' natural curiosity and the desire to move and be active around things and people surrounding them". Most likely, after this input enabled by face-to-face communication, the students, themselves, were empowered to suggest how the components of this concept may relate to each other. They offered their own interpretation, including evaluating and raising dilemmas as per the practicality of this HAES concept: “On the one hand we should enable the child to be active, curious and energetic in the classroom/school environment; on the other hand, there are boundaries in the classroom/school environment and you can't always allow a child to be active... the actual time the child is passive should be limited; one hour, for example, for the child to be busy at computer games, and he/she decides when [to be inactive]" (freedom with limitation).

Accepting natural diversity in body shape and size and the ineffectiveness and dangers of dieting for weight loss: The student teachers evaluated and judged positively the concept of accepting natural diversity in body shape and size. They suggested living peacefully and accepting our bodies as they are. These elements were reorganized into new thought patterns by the student teachers completing the CMC. This allowed for the realization and expression of their personal narratives as per how a child accepts this diversity: "Children accept the diversity of their body size and then they accepts others"; and "As a child I was always taught that everybody is equal, despite the diversity in size, shape or weight, a view that I still hold today. In a world where everyone worships thinness and thin people, it is important to allow for a natural and normal view of people who are bigger. It is important to remember that not everyone is capable of losing weight and not everyone wants to" and "We must release ourselves from the wrong perception that thin is better, healthier and more beautiful, while fat isn't nice. There is no such thing as 'thinness is sacred and fatness is disgusting', but the acceptance of the notion of one's body which is vibrant, a body which is beloved".

While the student teachers using the electronic module expressed more of their own feelings and personal experiences, the students who participated in the face-to-face groups dealt more with the conceptual messages that should be adopted by schools and conveyed to parents and pupils. One face-to-face group member emphasized the belief that: "The importance of and preference for a certain weight shouldn't be given. I think about the children's mental health. Teach them to love their body, their soul and lead healthy lifestyles without focusing on the weight'. This conceptual thinking may have been the result of further mediation on the part of the facilitators, who raised potential dilemmas relating to instilling the concept of natural diversity in body shape and size. 
Participants considered the dilemma arising from the contradiction of this HAES concept by new school health programs and policies that place emphasis upon differentiating between healthy and unhealthy foods and between foods that are better for maintaining children's weight. After retrieving, recognizing, and constructing meaning from the HAES concept of accepting natural diversity in body shape and size introduced by the facilitators, the students who participated in the verbal communication group evaluated and negatively judged those potential practical situations arising from implementation of the school policies described. Participants said: "They can jeopardize the child's and parents' right to hold different views and will create body or shape related stereotypes"; and "In other words those school efforts are transmitting a message that different is no good and it is important to transmit the message that diversity is a good thing".

Using feedback and social influence cues for directing the discussion, the moderators of the face-to-face group triggered the students to conceptualize even higher ideas regarding potential school health policies: "If a school implements a new health policy, what will be of importance to emphasize throughout, in your opinion? Are you concerned about school health policies and rules? Can you influence change leading to school health policies refraining from deciding what is right and what is wrong?" These triggers caused the student participants to express more freely their views about school health frameworks, which as one student expressed: "They can lead to a way where everyone can be different, to encourage and respect diversity, thus to respect ourselves". Or as another student explained: "There is autonomy, there is right, there is a choice, we must be mindful not to disrupt the family structure and to develop self-awareness, to respect, to listen and not to bind, to accept changes. To develop a program that allows, not forbids, and that doesn't instruct what and how to eat".

The socio-cultural influence cues for controlling the face-to-face discussion even empowered some of the Druze students taking part in the brainstorming and focus groups to reject some disparate socio-cultural norms regarding what is considered acceptable body shape and size and active body embodiment for boys and girls in their Druze culture today. One Druze student complained to the group: "In our culture, girls are not allowed to gain weight, but for boys it is normal, they are allowed". The moderator continued to empower the students to challenge this socio-cultural norm by asking: "What can you do against the influence of your culture and the socio-cultural pressure linking gender with expected body shape and size?" Empowered by the moderator, the female Druze students participating in the face-to-face group stood up for their own rights arguing: "Boy or girl, at the end of the day it's a human soul and they should be considered socially equal and not according to their physical weight". Similarly, the students felt empowered sufficiently to complain in the group about the treatment in Druze culture of sons as kings, with the mother and sisters serving him his food, though the community's attitude has been changing as they grow older.

Relaxed eating in response to internal body cues and the connection of relaxed eating to one's health and emotional status: A student completing the electronic module clarified: "Relaxed eating can facilitate the digestion of food in a way that is better for our body". Similarly, another student entered the following in her electronic module: "Relaxed eating can facilitate the food being digested in a more effective way and enable satiety to be felt. When a person feels satiety he/she transfers this feeling to his/her immune system and thus makes the immune system stronger. On the other hand, a person who eats fast and doesn't allow the food to be digested in an effective way will feel satiety for a short period of time and soon after will feel hungry. Such a thing can affect one's immunity and can make it weak". When capturing human perceptions and personal narratives related to HAES concepts or elements, it is not our purpose to investigate or critique whether those subjective perceptions have some physical or medical truth, as the proof of medical, metabolic, or physical evidence for those perceptions is not in the scope of this research. Another female student recording in her electronic module attributed meaning to the importance of relaxed eating in this way: "We must explain the meaning of relaxed eating to children, restrained and not binge eating, so they can sense the feeling of satiety. When we eat in moderation and in relaxation usually the digestive process is better and we enable the body to feel satiety. On the other hand, food that is eaten while we are stressed can cause digestive problems and often is rejected by the body".

The student teachers completing the electronic module focused more on internal processes related to individual feelings and the contribution of relaxed eating to the response of internal body cues or body signs. In contrast, the student teachers participating in the face-to-face interventions focused more on external support that can connect children to their body cues of satiety and hunger. For example: "We should ensure that children are kept busy with other activities that can focus their thoughts on things other than food' or 'To remind children of the previous times when they weren't hungry for food but 'hungry' for playing and that's how we can maintain children's awareness of their body's sensation of hunger or satiety". 
Contribution of social, emotional and spiritual factors to health and happiness: After breaking down this HAES concept into its constituent parts, and creating a new pattern or structure from its sub-elements, some students clarified on their electronic module: "When one is satisfied on a social, physical and spiritual level he or she turns into a happier and healthier person with better self-esteem. These qualities enable one to accept oneself with love and, at the same time, to appreciate and accept others".

Adhering not only to their individual beliefs, but also contemplating their future role as educators, the student teachers who took part in the focus group suggested some educational ways to stress the connection between happiness and body acceptance. One stated: "The happy person is a healthy person, so that's why each person should accept him or herself and believe that one's diversity is unique so one can be happy and healthy. For example, in school the teacher could invite each child to talk about his or her body in front of the whole class, what they like about their own body and what is special about it. In this way, the teacher encourages the child to love his or her own body and enforce the rest of the children to accept the body of their classmates as is". This last notion expressed by a Druze student who participated might reflect a pitfall of the direct communication style used when not all of the participants are fluent in the language used. Here, a Druze student expressed herself in Hebrew, which is the academic language used in the teacher training programs in the Northern Israel and Jordan Valley districts, and not in her mother tongue which is Arabic. It is assumed that the Druze student might or could have found better phrasing in her own mother tongue to express how the teacher could have created an atmosphere for accepting different body shapes and diversity in the class without using words such as "enforce the rest of the children to accept the body of their classmates as is", which might be perceived as too imposing and authoritarian.

\subsection{Affective Domain}

The second set of themes relate to the objectives of Bloom's affective domain. They include the ability of the student teachers to react emotionally, and the manner in which they express feelings, attach values and appreciate the concepts of the HAES paradigm. One student demonstrated partial appreciation of HAES values by writing on her electronic module: "It is important that in this war the emphasis is on eating healthy and nutritious food, diverse physical activities and obesity prevention rather than on emphasizing different diets". This statement only partially appreciates HAES values, as HAES does not impose a war on obesity; it emphasizes acceptance of the natural diversity between us all in shape and size. Another student demonstrated greater appreciation of HAES values when she wrote the following on her electronic module: "This occupation (referring to diets) can intensify problems like Anorexia, social isolation of overweight or obese people and, in the long run, will only lead to having more overweight or obese people. I would have preferred the declaration of increased exercise during childhood as a priority goal, which would be an acceptable means for solving the problem of future self-esteem so often due to being overweight. In my opinion, children should be educated to eat healthy and in the right way, while eating slowly, sitting, relaxed, etc., which enables more effective digestion of food. That is the way we can prevent the future war". The student most likely meant the future war against obesity, indicating that this student does not yet fully appreciate the HAES paradigm.

Closer to fully appreciating HAES values in this respect was the idea expressed by a Druze student participating in the face-to-face group moderated by the researchers. She stated her own personal belief as well as her commitment to others with respect to this value, most probably as a future educator: "A healthy lifestyle isn't about how much we have lost or gained weight and dieting, rather I can convey the subject through instructions, understanding the subject, including a lot of reading on the subject, explaining to people what it means to be healthy, to deliver a message, to help them by explaining how to treat the problem without affecting one health". Even though the student stated that healthy lifestyle is not about weight gain and dieting, it is not completely clear that she fully appreciates the HAES concept that obesity is not intrinsically a problem and that developing preventative and corrective measures to control children's eating habits is not the primary goal. Another student stated: "In my opinion, it is important to integrate, it is possible in my view to raise the awareness of the population regarding those issues in diverse ways, i.e. by emphasizing the love and acceptance for one's own body". Other students continued to cling to obesity prevention: "The middle road between both attitudes is to raise awareness among the children and teach them how to eat right and about the importance of sport for our bodies, that's the way obesity can be prevented".

Nonetheless, it appears that some of the ideas expressed by the Druze students throughout the brainstorming 
and smaller focus groups are closer to fully appreciating and comprehending HAES concepts than the ideas expressed by participants in the CMC. This may be the result of being exposed to more verbal interpretation and clarification by the moderators as to what HAES promotes than the CMC group participants.

\subsection{Psychomotor Domain}

The third set of themes relate to Bloom's psychomotor domain and include the student teachers set or readiness and mind-sets to act or volunteer in response to different situations related to the HAES paradigm. Moving further through the psychomotor domain to origination, the themes include the ability to construct a new theory or develop a new and comprehensive training program in relation to the HAES worldview. The students' readiness to act and mind-sets changed from a fear to discuss these issues with the children to actively planning how to develop a comprehensive program from a place of confidence. One of the Jewish students wrote in her reflection dairy: “Before I was exposed to the HAES worldview I wouldn't have implemented the related topics in my educational agenda for fear that I may harm the children. Instead, I would have left the teaching of the subject to another teacher. Now that I have been exposed to the HAES concepts and ways of handling the related topics and what to avoid in my teaching, I have the courage to teach the subject, but first, of course, I need to enrich my knowledge in the related areas". The Druze students in the face-to-face group also changed their set or readiness and mind-set to act. One student wrote in her reflection diary: "Dealing less with what is healthy and what is not healthy, but focusing more on accepting the body and recognizing internal feelings of satiety and hunger; encouraging the children to love their body as is and to accept the diversity in others". Another Druze student wrote: "Before I was exposed to HAES, I was focusing on healthy and non-healthy foods and their ingredients. But now I'm focusing on accepting the body as is and engaging in activities and lessons that encourage the children to love their body as is and accept the differences between us, as well as how to recognize our different body cues".

Some students moved through the psychomotor domain to origination to construct a new theory, and three Druze and one Jewish student actually developed a new and comprehensive training program in relation to the HAES worldview. While the Druze students were more focused on cultural issues and saw the parents, in partnership with the educational team, as one of the most important triggers for changing concepts, the Jewish students saw themselves and the teachers as the key agent for changing concepts. Two Druze students developed and constructed a program that was taught for a whole week in their training internship. One of them launched her program by brainstorming with the children. She drew a big sunshine on the blackboard in which she listed the children's ideas of the meaning of healthy nutrition. Among the Jewish students, only one chose to develop a program related in part to HAES concepts for her internship. In her reflection diary she wrote about the importance of listening to the body: "I realized the importance of listening to the body. It was important for me to emphasize in my class the importance of 'listening to the body' and even more it was raised by the pupils themselves. I was particularly happy when this concept was raised by a pupil who usually doesn't participate in the lessons".

\section{Discussion}

The purpose of this research was to assess whether and how the participating student teachers shifted across the praxis of skills in the learning domains of Bloom's taxonomy in relation to the HAES paradigm and its concepts. It also tested how two different communication strategies, verbal face-to-face brainstorming with focus groups and electronic CMC sessions, either promoted or impeded the evaluation or creation of new applications of the HAES paradigm. Content analysis was based on three sources: the students' reflection diaries that were recorded electronically in the CMC module or its related blog, the electronic CMC sessions, and transcripts of dialogues from the verbal face-to-face brainstorming group and smaller focus groups. The analysis highlighted themes and narratives indicating the participants' movement across the levels of Bloom's learning domains [27] as they learned to appreciate, judge, evaluate and even partially or initially apply HAES concepts.

Student teachers in both the face-to-face communication and electronic communication groups were exposed to new knowledge in the form of HAES theoretical concepts and related practical dilemmas. The participants in the face-to-face group received that knowledge from moderators, the researchers of this study. Throughout the process of dialogue during the brainstorming sessions, the moderators clarified, interpreted and "colored" or shaped the information they conveyed. Student teachers who used the electronic mediated CMC module had to 
interpret and respond to the knowledge introduced online without any human mediation contributing to or impeding the evaluation of HAES theoretical concepts and practical scenarios to which they were exposed for the first time. The human moderators of the face-to-face group contributed their own interpretations, world views, and experiences of HAES concepts and related scenarios. This mediation might have contributed to the students' immediate comprehension and critical valuing of the HAES theoretical concepts and practical dilemmas that were raised by the researchers and their peers. Significantly more critical evaluation and high-quality solutions based on human dialogue and exchanges were produced in the face-to-face group. This result is consistent with findings of other studies [28]-[30].

The students in the face-to-face group evaluated and created a new pattern and structure of knowledge from the elements of the HAES concept relating to acceptance of natural diversity in body shape and size (as opposed to emphasizing weight loss or weight maintenance). Mediation by the researchers and group peers in the face-to-face communication model might have prompted participants to respond immediately to impediments that may arise when introducing this alternative HAES concept in school health programs focused on conventional weight loss and maintenance. Current school health programs are conventional in the sense that they emphasize the theme of healthy eating by teaching which foods are healthy and which foods are not, and by placing emphasis on foods that are better or worse for maintaining children's weight.

Apparently, in the electronic CMC model the students had more of their own time and personal space to deal with HAES concepts emotionally, freely developing feelings, attaching values, developing appreciation for and changing attitudes toward HAES. The results confirm prior studies, indicating that the social presence element in face-to-face groups is associated with conforming to the group's narrative, while the most significant characteristic of online communication is the variance in the cognitive expression of the respondents [20]. It appears that the Jewish student teachers who were in the CMC group expressed their ideas while integrating the cognitive processes and motivational states, which might have led to a more efficient and personalized adaptation [31] [32] of HAES concepts.

Still, while the CMC students were free to present their perception of HAES online, that freedom of expression may have contributed to limiting their comprehension of the HAES conceptual worldviews and practical scenarios. In contrast, the students who participated in the brainstorming session benefitted from having the HAES theoretical concepts and related practical scenarios presented to them directly by the researchers, who also moderated the brainstorming session, contributing to its effect [28]. The brainstorming session was followed by further direct, face-to-face peer discussions of the HAES related concepts and scenarios, while the researchers and the Druze teacher consultant were available to listen and facilitate the understanding of participants when asked.

Based on the results, it might be worthwhile to examine the integration of the two different communication models. Both the face-to-face and CMC groups were comprehensive in their efforts to develop the HAES elements into a new pattern or structure. Both groups agreed on the ineffectiveness and dangers of dieting for weight loss and the importance of relaxed eating in response to internal body cues, thus supporting the critical contribution of social, emotional, and spiritual as well as physical factors to health and happiness [3]. Both models of communication triggered the initiation of some psychomotor skills while responding to different situations related to HAES world views. Participants even initiated the construction of a new theory and development of a new training program in the school setting teaching the HAES worldview.

However, throughout the direct face-to-face brainstorming it seemed as if the participating Druze student teachers responded primarily to the dilemmas raised by the researchers and were quick to join the expressed group norms when solving concrete problems and situations raised by others. Studies have shown that barriers such as social group pressure can limit the productivity of brainstorming groups [33] [34], but brainstorming can also be one of the most effective ways of overcoming social loafing and evaluation apprehension [35].

On a socio-cultural level, it was apparent that the Druze students were more concerned with highlighting the role of the women, particularly mothers and sisters, in influencing children's eating choices. This finding is supported by research indicating the variety of intrapersonal factors that can influence the individuals within groups. These factors include various personality characteristics [17] and diversity of cognitive styles [36], as well as gender and cultural differences [18] [30]. It was most likely shared personal qualities that empowered the Druze participants, all women, to state that they would like to see more of a role reversal. They want men to share the burden of ensuring that children eat healthily, are physically active, and become increasingly more aware and capable of independently adopting a healthy lifestyle. 
Desire for such a role reversal correlates with current socio-cultural transitions away from traditional expectations that Druze women in Israel must get married and take on domestic roles, and from stigmas attached to Druze women seeking higher education. The educational imbalance in favor of women creates an interesting tension, reflected through the brainstorming session in this research, in a society where women's roles are very circumscribed [37]. Israeli Jewish women are considered freer to reject the traditional role of women. This may explain the Jewish student teachers' use of the electronic space in the CMC module to focus on how they see themselves making the shift in enabling teachers, children, and communities to become more proactive in developing HAES paradigms further.

\section{Conclusions}

This research tested the teaching of the HAES paradigm to students in a local college teacher training program in northern Israel. Despite its local context, the findings have important global implications. The research employed two different communication models and succeeded in integrating academic training, theoretical concepts, and professional practices in a meaningful and inclusive way while producing the desired outcomes, the kind of meaningful and inclusive integration as implied by Hart and Wolf [38]. The method implemented empowered the participating student teachers to suggest practical solutions to conflicts between the HAES paradigm and concepts and national or global sociopolitical ideologies advocating conventional weight management paradigms aimed at controlling or fighting childhood obesity. The student teachers were challenged to raise personal and professional dilemmas and demonstrated movement to a higher praxis of thinking with regard to the HAES paradigm and concepts. They shifted from accepting national and global conventional approaches to fighting or preventing obesity, and moved toward developing more constructive, local and socio-culturally based solutions or ideologies supporting a natural appreciation for the differences in one's eating choices, body, image, size and self-worth.

The ideas of the face-to-face brainstorming group members remained more or less consistent with the group norms. The members also generated fewer ideas given the presence of an authority figure [19] and were anxious about social interactions [15] with the others. However, they also raised more practical dilemmas related to the HAES paradigm and to experiences at their school internships and with their families. When doing so, they remained detached from the narratives of the researchers and other group members.

The integration of both electronic CMC and direct face-to-face moderated communication was shown to be ideal when introducing new socio-cultural concepts and even socio-political ideologies into teacher training relating to future professional practices in the school setting and to personal development. The contextual level at which the socio-cultural dilemmas and certain socio-political ideologies related to HAES paradigms were constructed throughout this research study took place in isolation across different ethnic groups in Israel: Druze, Jewish and Bedouin. From a socio-cultural or socio-political perspective it is recommended to integrate the Druze, Jewish and Bedouin student teachers, their instructors, and educational consultants in the next phase of implementing the HAES concepts during the teacher training process.

Reflecting further on the socio-cultural context of this research study, the researchers who moderated the face-to-face brainstorming and designed the CMC module do not control Arabic at a mother tongue or second language level. All challenges, dilemmas, and communications related to the HAES paradigm were introduced to all research participants in Hebrew. Thus, a linguistic limitation was created for the Druze and Bedouin students whose mother tongue is Arabic. This limitation most likely impeded their movement across the praxis of Bloom's taxonomy in relation to HAES concepts and made it harder for the researchers to interpret and classify their verbal and written communication about the HAES paradigm.

\section{References}

[1] Bacon, L. and Aphramor, L. (2011) Weight Science: Evaluating the Evidence for a Paradigm Shift. Nutrition Journal, 10, 2891-2903. http://dx.doi.org/10.1186/1475-2891-10-9

[2] Robison, J. (2005) Health at Every Size: Toward a New Paradigm of Weight and Health. Medscape General Medicine, 7, 13.

[3] Dewey, J. (1964) John Dewey on Education: Selected Writings. In: Archambault, R.D., Ed., Modern Library Random House, New York.

[4] Kaufman, S. (1992) Integrating Theory and Practice and Preparation in Teacher Training Colleges. Mofet Institute, Je- 
rusalem. (In Hebrew)

[5] Feiman-Nemser, S. and Buchmann, M. (1989) Describing Teacher Education: A Framework and Illustrative Findings from a Longitudinal Study of Six Students. The Elementary School Journal, 89, 365-377. http://dx.doi.org/10.1086/461580

[6] Collins, W.S. (2011) Big Retailers Make Pledge of Stores for “Food Deserts”. New York Times, July 21, A15.

[7] Sahar, G. (2011) School Year Will Mark a Healthy Lifestyle. Israel Ministry of Education Web Site. http://cms.education.gov.il/EducationCMS/Units/Owl/Hebrew/AlSederHayom/OrachHaimBarei.htm

[8] Gronlund, N. (1985) Measurement and Evaluation in Teaching. MacMillan, New York.

[9] Harrow, A.J. (1972) A Taxonomy of the Psychomotor Domain: A Guide for Developing Behavioral Objectives. McKay, New York.

[10] Simpson, E.J. (1972) The Classification of Educational Objectives in the Psychomotor Domain. Gryphon House, Washington DC.

[11] Krathwohl, D.R., Bloom, B.S. and Masia, B. (1964) Taxonomy of Educational Objectives: The Classification of Educational Goals, Handbook 2: Affective Domain. McKay, New York.

[12] Krathwohl, D. (2002) A Revision of Bloom's Taxonomy: An Overview. Theory into Practice, 41, 212-218. http://dx.doi.org/10.1207/s15430421tip4104_2

[13] Anderson, L.W. and Krathwohl, D.R., Eds. (2001) A Taxonomy for Learning, Teaching and Assessing: A Revision of Bloom's Taxonomy of Educational Objectives. Complete Edition, Chap. 8-13, Longman, New York.

[14] Kiesler, S., Siegel, J. and McGuire, T.W. (1984) Social Psychological Aspects of Computer-Mediated Communication. American Psychologist, 39, 1123-1134. http://dx.doi.org/10.1037/0003-066X.39.10.1123

[15] Camacho, L.M. and Paulus, P.B. (1995) The Role of Social Anxiousness in Group Brainstorming. Journal of Personality and Social Psychology, 68, 1071-1080. http://dx.doi.org/10.1037/0022-3514.68.6.1071

[16] Diehl, M. and Stroebe, W. (1991) Productivity Loss in Idea-Generating Groups: Tracking down the Blocking Effects. Journal of Personality and Social Psychology, 61, 392-303. http://dx.doi.org/10.1037/0022-3514.61.3.392

[17] Jablin, E.M. and Seibold, D.R. (1978) Implications for Problem Solving Groups of Empirical Research on Brainstorming: A Critical Review of the Literature. Southern Speech Communication Journal, 43, 327-356. http://dx.doi.org/10.1080/10417947809372391

[18] Lamm, H. and Trommsdorf, G. (1973) Group versus Individual Performance on Tasks Requiring Ideational Proficiency (Brainstorming): A Review. European Journal of Social Psychology, 3, 361-387. http://dx.doi.org/10.1002/ejsp.2420030402

[19] Mullen, B., Johnson, C. and Salas, E. (1991) Productivity Loss in Brainstorming Groups: A Meta-Analytic Integration. Basic and Applied Social Psychology, 12, 3-23. http://dx.doi.org/10.1207/s15324834basp1201 1

[20] Shea, P. and Bidjerano, T. (2009) Community of Inquiry as a Theoretical Framework to Foster "Epistemic Engagement” and “Cognitive Presence" in Online Education. Computers Education, 52, 543-553. http://dx.doi.org/10.1016/j.compedu.2008.10.007

[21] Dougiamas, M. (1998) A Journey into Constructivism. http://dougiamas.com/writing/constructivism.html

[22] Dougiamas, M. and Taylor, P.C. (2000) Improving the Effectiveness of Tools for Internet-Based Education. Teaching and Learning Forum. https://dougiamas.com/writing/tlf2000/

[23] Halm, M., Olivier, B., Farooq, U. and Hoadley, C. (2005) Collaboration in Learning Design Using Peer-to-Peer Technologies. In: Koper, R. and Tattersall, C., Eds., Learning Design, Springer-Verlag, Berlin, 203-213. http://dx.doi.org/10.1007/3-540-27360-3_11

[24] Walter, O. and Ezra, R. (2012) Health at Every Size (HAES): A Challenge in Higher Education to Communicate the Weight on Our Mind. Articles, Creative Research and Art, 3, 60-63.

[25] Ezra, R. (2007) Children’s Eating and Weight Concepts: Communications and Conflicting Cultures. PhD Dissertation, Anglia Ruskin University, Cambridge \& Chelmsford.

[26] Ezra, R. (2010) Shifting the Paradigms: Communicating the Weight or Reducing the Weight on Children's Minds [Audio Recording]. In: Cooper, C., Ed., Seminar 2: Fat in the Clinic and Health at Every Size (HAES), Warwick University, 13-14 May 2010. http://www.dur.ac.uk/geography/research/researchprojects/fat_studies_and_health_at_every_size/seminars/seminar_two

[27] Bloom, B.S. (1956) Taxonomy of Educational Objectives, Handbook: The Cognitive Domain. David McKay, New York.

[28] Brown, V.R. and Paulus, P.B. (2002) Making Group Brainstorming More Effective: Recommendations from an Associative Memory Perspective. Current Directions in Psychological Science, 11, 208-212. 
http://dx.doi.org/10.1111/1467-8721.00202

[29] Firestien, R.L. and McCowan, R. (1988) Creative Problem Solving and Communication Behavior in Small Groups. Creativity Research Journal, 1, 106-114. http://dx.doi.org/10.1080/10400418809534292

[30] Isaksen, S.G. and Gaulin, J.P. (2005) A Reexamination of Brainstorming Research Implications for Research and Practice. Gifted Child Quarterly, 49, 315-329. http://dx.doi.org/10.1177/001698620504900405

[31] Cocea, M. and Weibelzahl, S. (2007) Eliciting Motivation Knowledge from Log Files towards Motivation Diagnosis for Adaptive Systems. In: Conati, C., McCoy, K. and Paliouras, G., Eds., User Modelling 2007. Proceedings of 11th International Conference, Corfu, 25-29 July 2007, 197-206. http://dx.doi.org/10.1007/978-3-540-73078-1_23

[32] Qu, L., Wang, N. and Johnson, W.L. (2005) Using Learner Focus of Attention to Detect Learner Motivation Factors. In: Ardissono, L., Brna, P. and Mitrovic, A., Eds., User Modelling 2005, Proceedings of 10th International Conference, Edinburgh, Scotland, Edinburgh, 24-29 July 2005, 70-73. http://dx.doi.org/10.1007/11527886_10

[33] Henningsen, D.D., Cruz, M.G. and Miller, M.L. (2000) The Role of Social Loafing in Pre-Deliberation DecisionMaking. Group Dynamics: Theory, Research, and Practice, 4, 168-175. http://dx.doi.org/10.1037/1089-2699.4.2.168

[34] Kerr, N.L. and Bruun, S.E. (1983) Dispensability of Member Effort and Group Motivation Losses: Free-Rider Effects. Journal of Personality and Social Psychology, 44, 78-94. http://dx.doi.org/10.1037/0022-3514.44.1.78

[35] Isaksen, S.C. (1998) A Review of Brainstorming Research: Six Critical Issues for Inquiry. Creative Research Unit, Creative Problem Solving Group, Buffalo.

[36] Priola, V., Smith, J.L. and Armstrong, S.J. (2004) Group Work and Cognitive Style: A Discursive Investigation. Small Group Research, 35, 565-595. http://dx.doi.org/10.1177/1046496404265143

[37] Schultz, R.G. (2012) Druze in Israel. http://www.myjewishlearning.com/israel/Contemporary_Life/Society_and_Religious_Issues/Arab-Israelis/druze.shtml

[38] Hart, A. and Wolff, D. (2006) Developing Local “Communities of Practice” through Local Community-University Partnerships. Planning, Practice \& Research, 21, 121-138. http://dx.doi.org/10.1080/02697450600901616 